\title{
Biomedical informatics and translational medicine
}

\author{
Indra Neil Sarkar
}

\begin{abstract}
Biomedical informatics involves a core set of methodologies that can provide a foundation for crossing the "translational barriers" associated with translational medicine. To this end, the fundamental aspects of biomedical informatics (e.g., bioinformatics, imaging informatics, clinical informatics, and public health informatics) may be essential in helping improve the ability to bring basic research findings to the bedside, evaluate the efficacy of interventions across communities, and enable the assessment of the eventual impact of translational medicine innovations on health policies. Here, a brief description is provided for a selection of key biomedical informatics topics (Decision Support, Natural Language Processing, Standards, Information Retrieval, and Electronic Health Records) and their relevance to translational medicine. Based on contributions and advancements in each of these topic areas, the article proposes that biomedical informatics practitioners ("biomedical informaticians") can be essential members of translational medicine teams.
\end{abstract}

\section{Introduction}

Biomedical informatics, by definition[1-8], incorporates a core set of methodologies that are applicable for managing data, information, and knowledge across the translational medicine continuum, from bench biology to clinical care and research to public health. To this end, biomedical informatics encompasses a wide range of domain specific methodologies. In the present discourse, the specific aspects of biomedical informatics that are of direct relevance to translational medicine are: (1) bioinformatics; (2) imaging informatics; (3) clinical informatics; and, (4) public health informatics. These support the transfer and integration of knowledge across the major realms of translational medicine, from molecules to populations. A partnership between biomedical informatics and translational medicine promises the betterment of patient care $[9,10]$ through development of new and better understood interventions used effectively in clinics as well as development of more informed policies and clinical guidelines.

The ultimate goal of translational medicine is the development of new treatments and insights towards the improvement of health across populations[11]. The first step in this process is the identification of what

neil.sarkar@uvm.edu

Center for Clinical and Translational Science, Department of Microbiology and Molecular Genetics, \& Department of Computer Science, University of Vermont, College of Medicine, 89 Beaumont Ave, Given Courtyard N309, Burlington, VT 05405 USA interventions might be worthy to consider[12]. Next, directed evaluations (e.g., randomized controlled trials) are used to identify the efficacy of the intervention and to provide further insights into why a proposed intervention works[12]. Finally, the ultimate success of an intervention is the identification of how it can be appropriately scaled and applied to an entire population[12]. The various contexts presented across the translational medicine spectrum enable a "grounding" of biomedical informatics approaches by providing specific scenarios where knowledge management and integration approaches are needed. Between each of these steps, translational barriers are comprised of the challenges associated with the translation of innovations developed through bench-based experiments to their clinical validation in bedside clinical trials, ultimately leading to their adoption by communities and potentially leading to the establishment of policies. The crossing of each translational barrier ("T1," "T2," and "T3," respectively corresponding to translational barriers at the bench-tobedside, bedside-to-community, and community-to-policy interfaces; as shown in Figure 1) may be greatly enabled through the use of a combination of existing and emerging biomedical informatics approaches[9]. It is particularly important to emphasize that, while the major thrust is in the forward direction, accomplishments, and setbacks can be used to valuably inform both sides of each translational barrier (as depicted by the arrows in Figure 1). An important enabling step to 


\section{Translational Medicine Continuum}

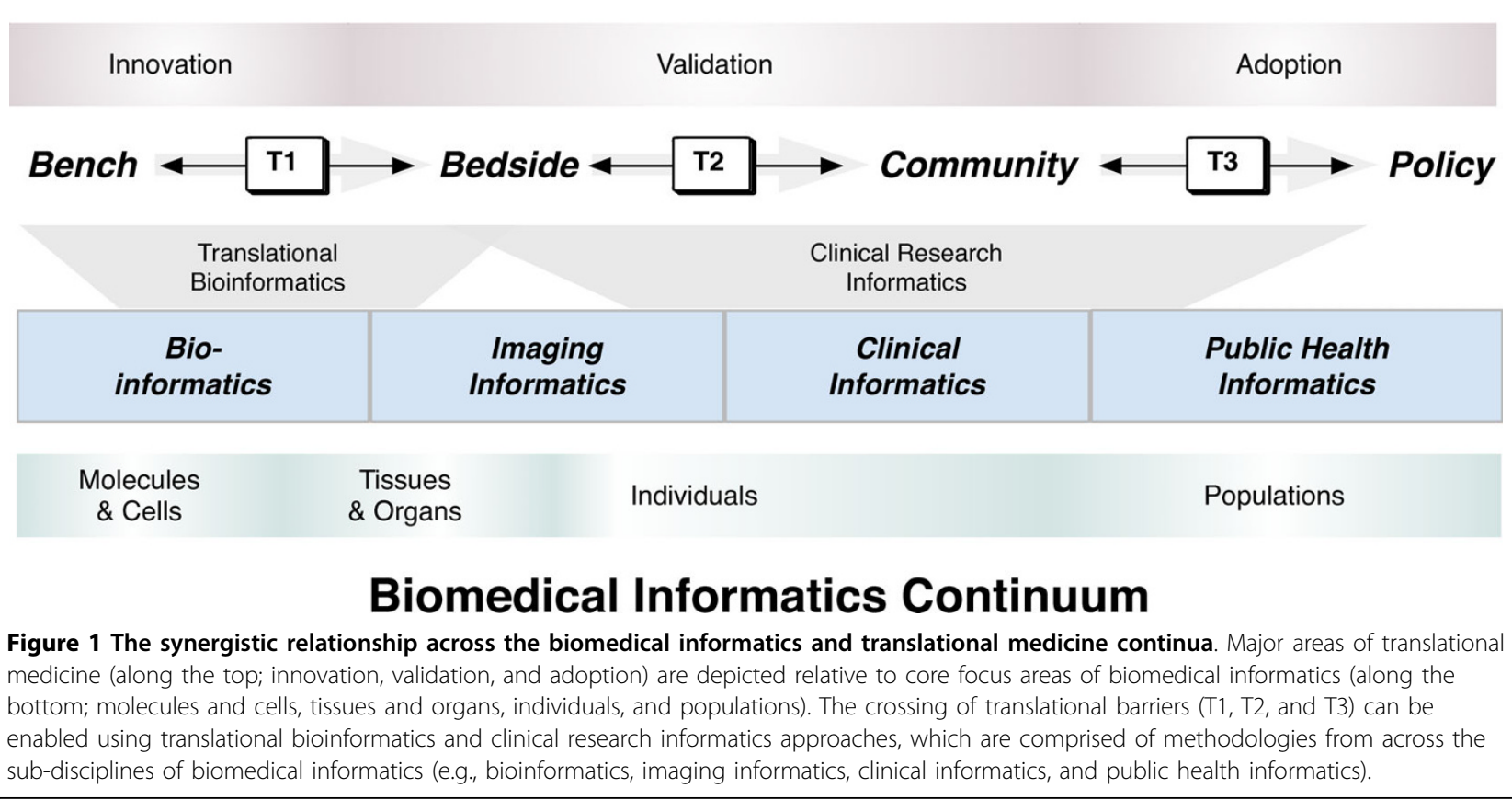

cross the translational barriers is the development of trans-disciplinary teams that are able to integrate relevant findings towards the identification of potential breakthroughs in research and clinical intervention[13]. To this end, biomedical informatics professionals ("biomedical informaticians") may be an essential addition to a translational medicine team to enable effective translation of concepts between team members with heterogeneous areas of expertise.

Translational medicine teams will need to address many of the challenges that have been the focus of biomedical informatics since the inception of the field. What follows is a brief description of biomedical informatics, followed by a discussion of selected key topics that are of relevance for translational medicine: (1) Decision Support; (2) Natural Language Processing; (3) Standards; (4) Information Retrieval; and, (5) Electronic Health Records. For each topic, progress and activities in bio-, imaging, clinical and public health informatics are described. The article then concludes with a consideration of the role of biomedical informaticians in translational medicine teams.

\section{Biomedical Informatics}

Biomedical informatics is an over-arching discipline that includes sub-disciplines such as bioinformatics, imaging informatics, clinical informatics, and public health informatics; the relationships between the sub-disciplines have been previously well characterized[7,14,15], and are still tenable in the context of translational medicine. Much of the identified synergy between biomedical informatics and translational medicine can be organized into two major categories that build upon the sub-disciplines of biomedical informatics (as shown in Figure 1): (1) translational bioinformatics (which primarily consists of biomedical informatics methodologies aimed at crossing the T1 translational barrier) and (2) clinical research informatics (which predominantly consists of biomedical informatics techniques from the $\mathrm{T} 1$ translational barrier across the $\mathrm{T} 2$ and $\mathrm{T} 3$ barriers). It is important to emphasize that the role of biomedical informatics in the context of translational medicine is not to necessarily create "new" informatics techniques[16]. Instead, it is to apply and advance the rich cadre of biomedical informatics approaches within the context of the fundamental goal of translational medicine: facilitate the application of basic research discoveries towards the betterment of human health or treatment of disease[17].

Clinical informatics has historically been described as a field that meets two related, but distinct needs[18]: patient-centric and knowledge-centric. This notion can be generalized for all of biomedical informatics within the context of translational medicine to suggest that the goals are either to meet the needs of user-centric stakeholders (e.g., biologists, clinicians, epidemiologists, and health services researchers) or knowledge-centric stakeholders (e.g., researchers or practitioners at the bench, bedside, community, and population level). Bioinformatics approaches 
are needed to identify molecular and cellular regions that can be targeted with specific clinical interventions or studied to provide better insights to the molecular and cellular basis of disease[19-25]. Imaging informatics techniques are needed for the development and analysis of visualization approaches for understanding pathogenesis and identification of putative treatments from the molecular, cellular, tissue or organ level[26-29]. Clinical informatics innovations are needed to improve patient care through the availability and integration of relevant information at the point of care[30-35]. Finally, public health informatics solutions are required to meet population based needs, whether focused on the tracking of emergent infectious diseases[36-39], the development of resources to relate complex clinical topics to the general population [40-44] or the assessment of how the latest clinical interventions are impacting the overall health of a given population[45-47].

At the T1 translational barrier crossing, translational bioinformatics is rapidly evolving with the enhancement and specialization of existing bioinformatics techniques and biological databases to enable identification of specific bench-based insights[16]. Similarly, clinical research informatics [48] emphasizes the use of biomedical informatics approaches to enable the assessment and moving of basic science innovations from the $\mathrm{T} 1$ translational barrier and across the $\mathrm{T} 2$ and $\mathrm{T} 3$ translational barriers (as depicted in Figure 1). These approaches may involve the enhancement and specialization of existing and new clinical and public health informatics techniques within the context of implementation and controlled assessment of novel interventions, development of practice guidelines, and outcomes assessment.

Translational bioinformatics and clinical research informatics are built on foundational knowledge-centric (i.e., "hypothesis-driven") approaches that are designed to meet the myriad of research and information needs of basic science, clinical, and public health researchers. The future of biomedical informatics depends on the ability to leverage common frameworks that enable the translation of research hypotheses into practical and proven treatments [49]. Progress has already been seen in the development of knowledge management infrastructures and standards to enable biomedical research to facilitate general research inquiry in specific domains (e.g., cancer[50] and neuroimaging[51]). It is also imperative for such advancements to be done in the context of improving user-centric needs, thereby improving patient care. To this end, the ability to manage and enable exploration of information associated with the biomedical research enterprise suggests that human medicine may be considered as the ultimate model organism [52]. Towards this aspiration, biomedical informaticians are uniquely equipped to facilitate the necessary communication and translation of concepts between members of trans-disciplinary translational medicine teams.

\section{Decision Support}

Decision support systems are information management systems that facilitate the making of decisions by biomedical stakeholders through the intelligent filtering of possible decisions based on a given set of criteria [53]. A decision support system can be any computer application that facilitates a decision making process, involving at least the following core activities [54]: (1) knowledge acquisition - the gathering of relevant information from knowledge sources (e.g., research databases, textbooks, or experts); (2) knowledge representation - representing the gathered knowledge in a systematic and computable way (e.g., using structured syntax[55-57] or semantic structures[58,59]); (3) inferencing - analyzing the provided criteria towards the postulation of a set of decisions (e.g., using either rule based[60] or probabilistic approaches[61]); and, (4) explanation - describing the possible decisions and the decision making process.

The leveraging of computational techniques to aide in decision-making has been well established in the clinical arena for more than forty years[62]. In bioinformatics, a range of systems have been developed to support bench biologist decisions, including sequence similarity[63], $a b$ initio gene discovery[64], and gene regulation[65]. There has been discussion of decision support systems that can incorporate genetic information in the providing of clinical decision support recommendations $[66,67]$. Decision support systems have been developed within imaging informatics for enabling better (both in terms of sensitivity and specificity) diagnoses of a range of diseases[68,69]. Clinical informatics research has given consideration to both positive and negative aspects of computer facilitated decision support [70-78]. Recent attention to bioterrorism planning and syndromic surveillance has also given rise to public health informatics solutions that involve significant decision support [79-81].

Decision support systems in the context of translational medicine will require a new paradigm of transdisciplinary inferencing approaches to cross each of the translational barriers. Inherent in the design of such decision support systems that span multiple disciplines will be the need for collaboration and cross-communication between key stakeholders at the bench, bedside, community, and population levels. To this end, there may be utility in decision support systems incorporating "Web 2.0" technologies[82], which enable Web-mediated communication between experts across disciplines. Such technologies have begun to emerge in scenarios where expertise and beneficiaries are inherently distributed, 
such as rare genetic diseases[83]. Regardless of the approach chosen, the fundamental tasks of knowledge acquisition, representation, and inferencing and explanation will be required to be done with members of the translational medicine team. The successful design of translational medicine decision support systems could become an essential tool to bridge researchers and findings across biological, clinical, and public health data.

\section{Natural Language Processing}

Natural Language Processing (NLP) systems fall into two general categories: (1) natural language understanding systems that extract information or knowledge from human language forms (either text or speech), often resulting in encoded and structured forms that can be incorporated into subsequent applications[84,85]; and, (2) natural language generation systems that generate human understandable language from machine representations (e.g., from within a knowledge bases or systems of logical rules)[86]. NLP has a strong relationship to the field of computational linguistics, which derives computational models for phenomena associated with natural language (encapsulated as either sets of handcrafted rules or statistically derived models)[87].

The development and application of NLP approaches has been a significant focus of research across the entire spectrum of biomedical informatics. Biological knowledge extraction has also been a major area of focus in NLP systems [88,89], including the use of NLP methods to facilitate the prediction of molecular pathways[90]. Within imaging informatics, there has been a range of applications that involve processing and generating information associated with clinical images that are often used to help summarize and organize radiology images[91-94]. In clinical informatics, there have been great advances in the extraction of information from semi-structured or unstructured narratives associated with patient care [95], as well as the development of applications for generating summaries or reports automatically[96-98]. In the realm of public health, NLP approaches have been demonstrated to facilitate the encoding and summarization of significant information at the population level, such as for describing functional status[99] and outbreak detection[100].

Peer-reviewed literature, such as indexed by MEDLINE, has been shown to be a source of previously unknown inferences across domains[101,102] as well as linkages between the bioinformatics and clinical informatics communities[103]. In addition to MEDLINE, which grows by approximately 1 million citations per year[104], the increasing adoption of Electronic Health Records will lead to increased volumes of natural language text[105]. To this end, NLP approaches will increasingly be needed to wade through and systematically extract and summarize the growing volumes of textual data that will be generated across the entire translational spectrum[106]. There has also been some work in NLP that directly strives to develop linkages across disparate text sources (e.g., bridging e-mail communications to relevant literature[107]). Within the realm of translational medicine, NLP approaches will be increasingly poised to facilitate the development of linkages between unstructured and structured knowledge sources across the realms of biology, medicine, and public health.

\section{Standards}

The task of transmitting or linking data across multiple biomedical data sources is often difficult because of the multitude of different formats and systems that are available for storing data. Standard methods are thus needed for both representing and exchanging information across disparate data sources to link potentially related data across the spectrum of translational medicine [108]- from laboratory data at the bench to patient charts at the bedside to linkage and availability of clinical data across a community to the development of aggregate statistics of populations. These standards need to accommodate the range of heterogeneous data storage systems that may be required for clinical or research purposes, while enabling the data to be accessible for subsequent linkage and retrieval. Standards are thus an essential element in the representation of data in a form that can be readily exchanged with other systems.

The development of standards to represent and exchange data has been a major area of emphasis in biomedical informatics since the 1980's[108-113]. Much energy has been placed in the development of knowledge representation constructs[109,114,115] (e.g., ontologies and controlled vocabularies), as well as establishment of standards for their use and incorporation in biological[116], clinical[117,118], and public health[119] contexts. For example, the voluminous data associated with gene expression arrays gave rise to the Minimum Information About Microarray Experiment (MIAME) standard by the bioinformatics community [120]. Within the imaging informatics community, the Digital Imaging and COmmunications in Medicine (DICOM) defines the international standards for representing and exchanging data associated with medical images[121]. Within the clinical realm, Health Level 7 (HL7) standards are commonplace for describing messages associated with a wide range of health care activities[122,123]. Specific clinical terminologies, such as the Systematized Nomenclature of Medicine-Clinical Terms (SNOMED CT) can be used to represent, with appropriate considerations[124,125], clinical information 
associated with patient care. Data standards have been developed for systematically organizing and sharing data associated with clinical research $[112,126]$, including those from HL7 and the Clinical Data Standards Interchange Consortium (CDISC). Within public health, the International Statistical Classification of Diseases and Related Health Problems (ICD) is a standard established by the World Health Organization (WHO) and used in the determination of morbidity and mortality statistics [127]. The rapid emergence of regional health information exchange networks has also necessitated that a range of standards be used to ensure the interoperability of clinical data[128-133]. The Comité Européen de Normalisation in collaboration with the International Organization for Standardization (ISO) is coordinating the common representation and exchange standards across the clinical and public health realms (through ISO/TC 215[134]).

The re-use of data in the development and testing of research hypotheses is a regular area of interest in biomedical informatics[126,135]. However, disparities between coding schemes pose potential barriers in the ability for systematic representation across biomedical resources[136]. Furthermore, the development of new representation structures is becoming increasingly easier [137], resulting in many possible contextual meanings for a given concept. The Unified Medical Language System (UMLS) [138] has demonstrated how it may be possible to develop conceptual linkages across terminologies that span the entire translational spectrum[139], from molecules to populations[114]. Additional centralized resources have been developed that facilitate the development and dissemination of knowledge representation structures that may not necessarily be part of the UMLS (e.g., the National Center for Biomedical Ontology[140] and its BioPortal[141]).

Standards that have been developed and are implemented by the biomedical informatics community will be an essential component towards the goal of integrating relevant data across the translational barriers (e.g., to answer questions like what is the comparative effectiveness of a particular pharmacogenetic treatment versus conventional pharmaceutical treatments in the general population?). Additionally, standards can facilitate the access and integration of information associated with a particular individual in light of available biological, imaging, clinical, and public health data (including improved access to these data from within medical records), ultimately enabling the development and testing the utility of "personalized medicine." Consequently, translational medicine will depend on biomedical informatics approaches to leverage existing standards (e.g., MIAME, HL7, and DICOM) and resources like the UMLS, in addition to developing new standards for specialized domains (e.g., cancer[142] and neuroimaging [143]).

\section{Information Retrieval}

Information retrieval systems are designed for the organization and retrieval of relevant information from databases. The basic premise is that a query is presented to a system that then attempts to retrieve the most relevant items from within database(s) that satisfy the request[144]. The quality of the results is then measured using statistics such as precision (the number of relevant results retrieved relative to the total number of retrieved results) and recall (the number of relevant results retrieved relative to the total number of relevant items in the database).

Across the field of biomedical informatics, various efforts have focused on the need to bring together information across a range of data sources to enable information retrieval queries[145,146]. Perhaps the most popular information retrieval tool is the PubMed interface to the MEDLINE citation database that contains information across much of biomedicine[147]. In addition to MEDLINE, the growth of publicly available resources has been especially remarkable in bioinformatics[148], which generally focus on the retrieval of relevant biological data (e.g., molecular sequences from GenBank given a nucleotide or protein sequence). Information retrieval systems have also been developed in bioinformatics that are able to retrieve relevant data from across multiple resources simultaneously (e.g., for generating putative annotations for unknown gene sequences[149]). Imaging information retrieval systems have been a rich research area where relevant images are retrieved based on image similarity[150] (e.g., to identify pathological images that might be related to a particular anatomical shape and related clinical context [151]). Within clinical environments, information retrieval systems have been developed that can link users to relevant clinical reference resources based on using the particular clinical context as part of the query (e.g., to identify relevant articles based on a specific abnormal laboratory result) $[152,153]$. Information retrieval systems have been developed in public health to identify relevant information for consumers, epidemiologists, and health service researchers given varying types of queries $[47,154,155]$. The procedural tasks involved with information retrieval often involve natural language processing and knowledge representation techniques, such as highlighted previously. The integration of natural language processing, knowledge representation, and information retrieval systems has led to the development of "question-answer" systems that have the potential to provide more user-friendly interfaces to information retrieval systems[156]. 
The need to identify relevant information from multiple heterogeneous data sources is inherent in translational medicine, especially in light of the exponential growth of data from a range of data sources across the spectrum of translational medicine. Within the context of translational medicine, information retrieval systems could be built on existing and emerging approaches from within the biomedical informatics community, including those that make use of contemporary "Semantic Web" technologies[157-159]. The ability to reliably and efficiently identify relevant information, such as demonstrated by archetypal information retrieval systems developed by the biomedical informatics community (e.g., GenBank and MEDLINE), will be crucial to identify requisite knowledge that will be necessary to cross each of the translational barriers.

\section{Electronic Health Records}

Medical charts contain the sum of information associated with an individual's encounters with the health care system. In addition to data recorded by direct care providers (e.g., physicians and nurses), medical charts typically include data from ancillary services such as radiology, laboratory, and pharmacy. With the increasing electronic availability of data across the health care enterprise, paper-based medical charts have evolved to become computerized as Electronic Health Records (EHRs). EHRs can capture a variety of information (e.g., by clinicians at the bedside) and have electronic interfaces to individual services (e.g., administrative, laboratory, radiology, and pharmacy). Many EHRs can enable Computerized Provider Order Entry (CPOE), which allows clinicians to electronically order services and may also enable real-time clinical decision support (e.g., provide an alert about an order that could lead to an adverse event[160]). Clinical documentation can be entered directly into EHR systems, allowing for potentially fewer issues due to transcription delays or difficulty in deciphering handwritten notes. An artifact of EHRs is the development of more robust clinical and research data warehouses, which can be used for subsequent studies[161-163].

From the earliest propositions of electronic health records[164,165], it has been thought that the potential benefits to support and improve patient care would been immense[166]. From a bioinformatics perspective, the integration of genomic information in EHRs may lead to genotype-to-phenotype correlation analyses $[167,168]$, and thus increase the importance of bioinformatics integration with laboratory and clinical information systems[169]. The ability to review radiological images or search for possible clinically relevant features within them has shown great promise by the imaging informatics community[170-174]. Recent attention to
EHRs has been given by the United States federal government as a core element of the modern reformation of health care[175]. Empirical studies will be needed to demonstrate the actual implications on patient care and effects on the reduction in overall health care costs as a direct result of EHR implementation[176,177]; however, there remains great interest in overall benefit of patient care and management to keep up with the dizzying pace of modern medicine within the clinical informatics community[176,178,179], including the development of integrated clinical decision support systems[66]. Public health informatics initiatives have pioneered surveillance projects for outbreak detection[180,181] or patient safety[182,183] that involve EHRs (which are also noted for their potentially high costs of implementation[184]). Recently, energy has also focused on the development of personal health records (PHRs) as a means to extend the realm of clinical care beyond the clinic into patient homes[185]. Through PHRs, consumers can be directly involved with their care management plans and as easily used as other electronic services (e.g., ATMs for banking[186] or using increasingly popular "Web 2.0" collaboration technologies[187]). Like EHRs, there is still need to assess the true benefits of PHRs in terms of their actual impact on the improvement of patient care $[188,189]$. The potential ubiquity of EHRs underscores the importance of considering the associated privacy and ethical issues (e.g., who has access to which kinds of data and for what purposes can clinical data actually be used for research or exchanged through regional interchanges)[189-193].

The increased availability of electronic health data, which are largely available and organized within EHRs, may have a significant impact on translational medicine. For example, the emergence of "personal health" projects (e.g., Google Health[117]) and consumer services (e.g., 23andMe[118]) has the potential to generate more genotype (i.e., "bench") and phenotype (i.e., "bedside") data that may be analyzed relative to community-based studies. The raw elements that could lead to the next breakthroughs may be made available as part of the data deluge associated with consumer-driven, "grass-roots" efforts. Such initiatives, in addition to the other core biomedical informatics topics discussed here (decision support, natural language processing, and information retrieval techniques), will enable the leveraging of EHRbased health data to catalyze the crossing of the translational barriers.

\section{The Role of the Biomedical Informatician in a Translational Medicine Team}

Translational medicine is a trans-disciplinary endeavor that aims to accelerate the process of bringing innovations into practice through the linking of practitioners 
and researchers across the spectrum of biomedicine. As evidenced by major funding initiatives (e.g., the United States National Institutes of Health "Roadmap"[194,195]), there is great hope in the development of a new paradigm of research that catalyzes the process from bench to practice. The trans-disciplinary nature of the translational barrier crossings in translational medicine endeavors will increasingly necessitate biomedical informatics approaches to manage, organize, and integrate heterogeneous data to inform decisions from bench to bedside to community to policy.

The distinctions between multi-disciplinary, inter-disciplinary, and trans-disciplinary goals have been described as the difference between additive, interactive, and holistic approaches[196-198]. Unlike multi-disciplinary or inter-disciplinary endeavors, trans-disciplinary initiatives must be completely convergent towards the development of completely new research paradigms. The greatest challenge faced by translational medicine, therefore, is the difficulty in truly being a trans-disciplinary science that brings together researchers and practitioners that traditionally work within their own "silos" of practice.

Formally trained biomedical informaticians have a unique education[199-205], often with domain expertise in at least one area, which is specifically designed to enable trans-disciplinary team science, such as needed for the success within a translational medicine team. There is some discussion over what level of training constitutes the minimal requirements for biomedical informatics training[200,201,206-214], including discussion about what combination of technical and non-technical skills are needed[2,215]. However, a uniform feature of all formally trained biomedical informaticians is, as shown in Figure 2, their ability to interact with key stakeholders across the translational medicine spectrum (e.g., biologists, clinicians/clinical researchers, epidemiologists, and health services researchers). Furthermore, biomedical informaticians bring the methodological approaches (depicted as the shadowed region in Figure 2), such as the five topics highlighted in earlier sections of this article, which can enable the

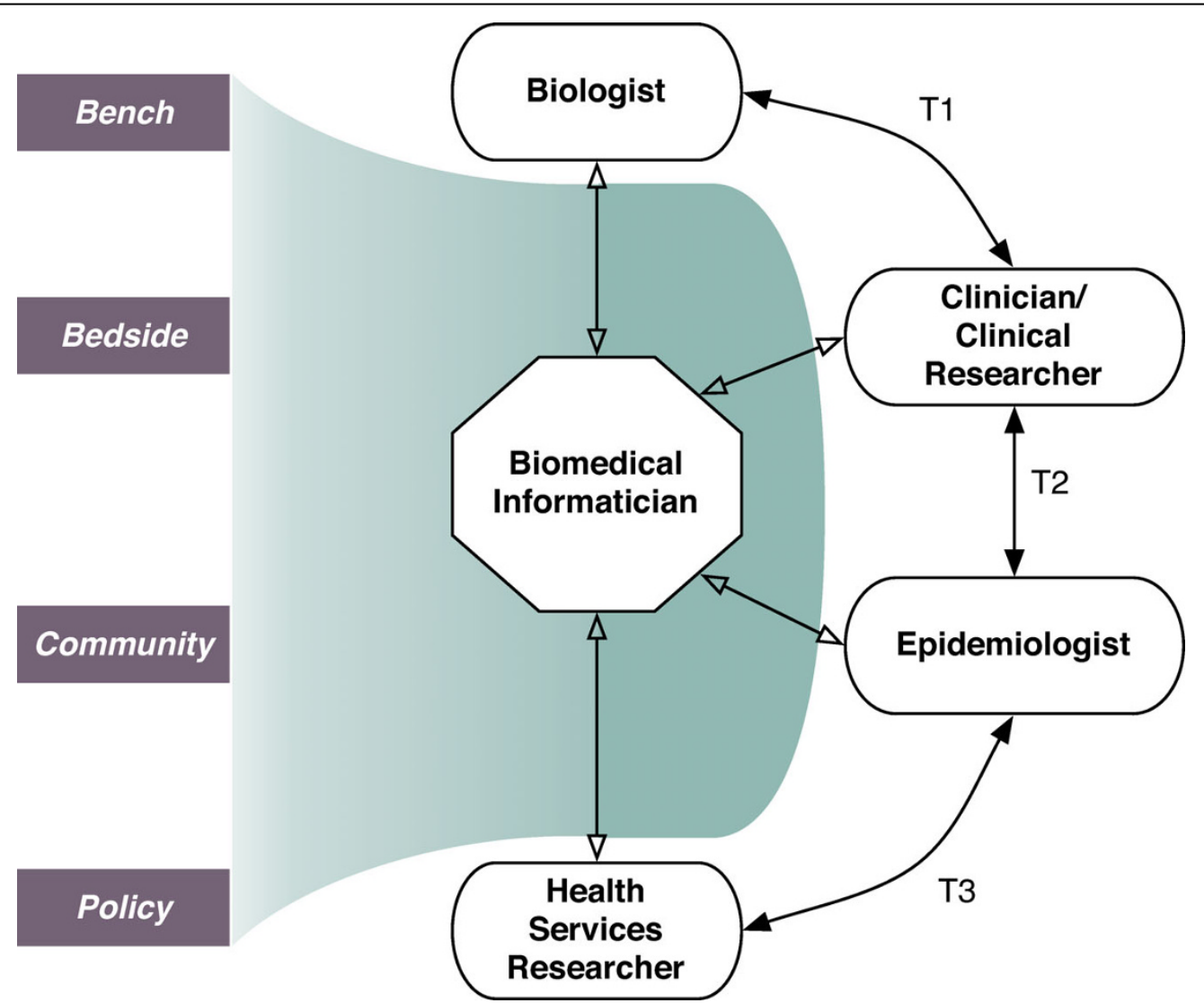

Figure 2 The role of the biomedical informatician in a translational medicine team. Biomedical informaticians interact with key stakeholders across the translational medicine spectrum (e.g., biologists, clinicians/clinical researchers, epidemiologists, and health services researchers). The suite of methods as described in this manuscript and depicted as the shadowed region enable the transformation of data from bench, bedside, community, and policy based data sources (shown in blocks). 
development and testing of new trans-disciplinary hypotheses. It is important to note that the topics discussed in this article are only a sampling of the full array of biomedical informatics techniques that are available (e.g., cognitive science approaches, systems design and engineering, and telehealth).

The success of translational medicine will depend not only on the addition of biomedical informaticians to translational medicine teams, but also on the acceptance and understanding of what biomedical informatics consists of by other members in the team. To this end, the importance of biomedical informatics training has been underscored as a key area of required competency across the spectrum of translational medicine, from biologists[216] to clinicians[217] to public health professionals[218]. There has been some demonstrable success in the development of experiences that focus on training "agents of change" with necessary core concepts[219] as well as hallmark distributed educational programs that aim to provide formal educational opportunities for biomedical informatics training[220]. The composition of translational medicine teams will also depend on the appropriate intermixing of biomedical informatics expertise to complement the requisite domain expertise[16]. To this end, the success of translational medicine endeavors may undoubtedly be greatly enhanced with biomedical informatics approaches; however, the appropriate synergistic relationship between biomedical informaticians and other members of the translational medicine team remains one of the next major challenges to be addressed in pursuit of translational medicine breakthroughs.

\section{Conclusion}

Since its beginnings, biomedical informatics innovations have been developed to support the needs of various stakeholders including biologists, clinicians/clinical researchers, epidemiologists, and health services researchers. A range of biomedical informatics topics, such as those described in this paper, form a suite of elements that can transform data across the translational medicine spectrum. The inclusion of biomedical informaticians in the translational medicine team may thus help enable a trans-disciplinary paradigm shift towards the development of the next generation of groundbreaking therapies and interventions.

\footnotetext{
Acknowledgements

The author thanks members of the Center for Clinical and Translational Science at the University of Vermont, especially Drs. Richard A. Galbraith and Elizabeth S. Chen, for valuable insights and discussion that contributed to the thoughts presented here. Gratitude is also expressed from the author to the anonymous reviewers who provided in-depth suggestions towards the improvement of the overall manuscript. The author is supported by grants
}

from the National Library of Medicine (R01 LM009725) and the National Science Foundation (IIS 0241229).

\section{Authors' contributions}

INS conceived of and drafted the manuscript as written.

\section{Competing interests}

The author declares that they have no competing interests.

Received: 21 July 2009

Accepted: 26 February 2010 Published: 26 February 2010

\section{References}

1. Shortliffe EH, Cimino JJ: Biomedical informatics: computer applications in health care and biomedicine New York, NY: Springer, 32006.

2. Greenes RA, Shortliffe EH: Commentary: Informatics in biomedicine and health care. Acad Med 2009, 84:818-820.

3. Bernstam EV, Hersh WR, Johnson SB, Chute CG, Nguyen H, Sim I, Nahm M, Weiner MG, Miller P, DiLaura RP, Overcash $M$, Lehmann HP, Eichmann D, Athey BD, Scheuermann RH, Anderson N, Starren J, Harris PA, Smith JW, Barbour E, Silverstein JC, Krusch DA, Nagarajan R, Becich MJ: Synergies and distinctions between computational disciplines in biomedical research: perspective from the Clinical andTranslational Science Award programs. Acad Med 2009, 84:964-970.

4. Collen MF: The origins of informatics. J Am Med Inform Assoc 1994, 1:91-107.

5. Collen MF: Fifty years in medical informatics. Yearb Med Inform 2006, 174-179.

6. Haux R: Individualization, globalization and health-about sustainable information technologies and the aim of medical informatics. Int J Med Inform 2006, 75:795-808.

7. Kuhn KA, Knoll A, Mewes HW, Schwaiger M, Bode A, Broy M, Daniel H, Feussner $\mathrm{H}$, Gradinger $\mathrm{R}$, Hauner $\mathrm{H}$, Hofler $\mathrm{H}$, Holzmann B, Horsch A, Kemper A, Krcmar H, Kochs EF, Lange R, Leidl R, Mansmann U, Mayr EW, Meitinger T, Molls M, Navab N, Nusslin F, Peschel C, Reiser M, Ring J, Rummeny EJ, Schlichter J, Schmid R, et al: Informatics and medicine-from molecules to populations. Methods Inf Med 2008, 47:283-295.

8. Embi PJ, Kaufman SE, Payne PR: Biomedical informatics and outcomes research: enabling knowledge-driven health care. Circulation 2009, 120:2393-2399.

9. Payne PR, Johnson SB, Starren JB, Tilson HH, Dowdy D: Breaking the translational barriers: the value of integrating biomedical informatics and translational research. J Investig Med 2005, 53:192-200.

10. Payne PR, Embi PJ, Sen CK: Translational informatics: enabling highthroughput research paradigms. Physiol Genomics 2009, 39:131-140.

11. Woolf $\mathrm{SH}$ : The meaning of translational research and why it matters. JAMA 2008, 299:211-213.

12. Westfall JM, Mold J, Fagnan L: Practice-based research-"Blue Highways" on the NIH roadmap. JAMA 2007, 297:403-406.

13. Bernstam EV, Hersh WR, Sim I, Eichmann D, Silverstein JC, Smith JW, Becich MJ: Unintended consequences of health information technology: A need for biomedical informatics. J Biomed Inform 2009.

14. Maojo V, Kulikowski C: Medical informatics and bioinformatics: integration or evolution through scientific crises?. Methods Inf Med 2006, 45:474-482.

15. Kukafka R, O'Carroll PW, Gerberding JL, Shortliffe EH, Aliferis C, Lumpkin JR, Yasnoff WA: Issues and opportunities in public health informatics: a panel discussion. J Public Health Manag Pract 2001, 7:31-42.

16. Butte AJ: Translational bioinformatics: coming of age. J Am Med Inform Assoc 2008, 15:709-714.

17. Baxter P: Research priorities: Bless thee! Thou art translated. Dev Med Child Neurol 2008, 50:323.

18. Hersh WR: Medical informatics: improving health care through information. JAMA 2002, 288:1955-1958.

19. Khoury MJ, Rich EC, Randhawa G, Teutsch SM, Niederhuber J: Comparative effectiveness research and genomic medicine: an evolving partnership for 21st century medicine. Genet Med 2009, 11:707-711.

20. Kirkwood SC, Hockett RD Jr: Pharmacogenomic biomarkers. Dis Markers 2002, 18:63-71.

21. Evans WE, Relling MV: Pharmacogenomics: translating functiona genomics into rational therapeutics. Science 1999, 286:487-491. 
22. Vizirianakis IS: Pharmaceutical education in the wake of genomic technologies for drug development and personalized medicine. Eur J Pharm Sci 2002, 15:243-250.

23. Ikekawa A, Ikekawa S: Fruits of human genome project and private venture, and their impact on life science. Yakugaku Zasshi 2001, 121:845-873.

24. Butler GS, Overall CM: Proteomic identification of multitasking proteins in unexpected locations complicates drug targeting. Nat Rev Drug Discov 2009, 8:935-948.

25. Rajcevic U, Niclou SP, Jimenez CR: Proteomics strategies for target identification and biomarker discovery in cancer. Front Biosci 2009, 14:3292-3303.

26. Ratib O: Imaging informatics: from image management to image navigation. Yearb Med Inform 2009, 167-172.

27. Arenson $\mathrm{RL}$, Andriole $\mathrm{KP}$, Avrin $\mathrm{DE}$, Gould RG: Computers in imaging and health care: now and in the future. J Digit Imaging 2000, 13:145-156.

28. Ratib O, Swiernik M, McCoy JM: From PACS to integrated EMR. Comput Med Imaging Graph 2003, 27:207-215.

29. Kuzmak PM, Dayhoff RE: The VA's use of DICOM to integrate image data seamlessly into the online patient record. Proc AMIA Symp 1999, 92-96.

30. Costa BM, Fitzgerald KJ, Jones KM, Dunning Am T: Effectiveness of ITbased diabetes management interventions: a review of the literature. BMC Fam Pract 2009, 10:72

31. Hersh WR, Wallace JA, Patterson PK, Shapiro SE, Kraemer DF, Eilers GM, Chan BK, Greenlick MR, Helfand M: Telemedicine for the Medicare population: pediatric, obstetric, and clinician-indirect home interventions. Evid Rep Technol Assess (Summ) 2001, 1-32.

32. Schreiber WE, Giustini DM: Pathology in the era of Web 2.0. Am J Clin Pathol 2009, 132:824-828.

33. Kawamoto K, Houlihan CA, Balas EA, Lobach DF: Improving clinical practice using clinical decision support systems: a systematic review of trials to identify features critical to success. BMJ 2005, 330:765.

34. Mollon B, Chong J Jr, Holbrook AM, Sung M, Thabane L, Foster G: Features predicting the success of computerized decision support for prescribing: a systematic review of randomized controlled trials. BMC Med Inform Decis Mak 2009, 9:11

35. Durieux P, Trinquart L, Colombet I, Nies J, Walton R, Rajeswaran A, Rege Walther M, Harvey E, Burnand B: Computerized advice on drug dosage to improve prescribing practice. Cochrane Database Syst Rev 2008, CD002894.

36. Frieden TR, Henning KJ: Public health requirements for rapid progress in global health. Glob Public Health 2009, 4:323-337.

37. Brownstein JS, Freifeld CC, Madoff LC: Digital disease detectionharnessing the Web for public health surveillance. N Engl J Med 2009, 360:2153-2155, 2157.

38. Barclay E: Predicting the next pandemic. Lancet 2008, 372:1025-1026.

39. Heymann DL, Rodier GR: Hot spots in a wired world: WHO surveillance of emerging and re-emerging infectious diseases. Lancet Infect Dis 2001, 1:345-353.

40. McDaniel AM, Schutte DL, Keller LO: Consumer health informatics: from genomics to population health. Nurs Outlook 2008, 56:216-223, e213.

41. Houston TK, Ehrenberger HE: The potential of consumer health informatics. Semin Oncol Nurs 2001, 17:41-47.

42. Pagon RA: Internet resources in Medical Genetics. Curr Protoc Hum Genet 2006, Chapter 9(Unit 9):12

43. Fomous C, Mitchell JA, McCray A: 'Genetics home reference': helping patients understand the role of genetics in health and disease. Community Genet 2006, 9:274-278.

44. Omenn GS: Public health genetics: an emerging interdisciplinary field for the post-genomic era. Annu Rev Public Health 2000, 21:1-13.

45. N AS: WHO EMRO's approach for supporting e-health in the Eastern Mediterranean Region. East Mediterr Health J 2006, 12(Suppl 2): S238-252.

46. Mandl KD, Lee TH: Integrating medical informatics and health services research: the need for dual training at the clinical health systems and policy levels. J Am Med Inform Assoc 2002, 9:127-132.

47. Revere D, Turner AM, Madhavan A, Rambo N, Bugni PF, Kimball A, Fuller SS: Understanding the information needs of public health practitioners: a literature review to inform design of an interactive digital knowledge management system. J Biomed Inform 2007, 40:410-421.
48. Embi PJ, Payne PR: Clinical Research Informatics: Challenges, Opportunities and Definition for an Emerging Domain. J Am Med Inform Assoc 2009, 16:316-327.

49. Butte AJ: Translational bioinformatics applications in genome medicine. Genome Med 2009, 1:64.

50. Oster S, Langella S, Hastings S, Ervin D, Madduri R, Phillips J, Kurc T, Siebenlist F, Covitz P, Shanbhag K, Foster I, Saltz J: caGrid 1.0: an enterprise Grid infrastructure for biomedical research. J Am Med Inform Assoc 2008, 15:138-149.

51. Keator DB, Grethe JS, Marcus D, Ozyurt B, Gadde S, Murphy S, Pieper S, Greve D, Notestine R, Bockholt HJ, Papadopoulos P: A national human neuroimaging collaboratory enabled by the Biomedical Informatics Research Network (BIRN). IEEE Trans Inf Technol Biomed 2008, 12:162-172.

52. Butte AJ: Medicine. The ultimate model organism. Science 2008, 320:325-327.

53. Osheroff JA, Teich JM, Middleton B, Steen EB, Wright A, Detmer DE: A roadmap for national action on clinical decision support. J Am Med Inform Assoc 2007, 14:141-145.

54. Duda RO, Shortliffe EH: Expert Systems Research. Science 1983, 220:261-268.

55. Hripcsak G, Ludemann P, Pryor TA, Wigertz OB, Clayton PD: Rationale for the Arden Syntax. Comput Biomed Res 1994, 27:291-324.

56. De Clercq P, Kaiser K, Hasman A: Computer-Interpretable Guideline formalisms. Stud Health Technol Inform 2008, 139:22-43.

57. Ohno-Machado L, Gennari JH, Murphy SN, Jain NL, Tu SW, Oliver DE, Pattison-Gordon E, Greenes RA, Shortliffe EH, Barnett GO: The guideline interchange format: a model for representing guidelines. J Am Med Inform Assoc 1998, 5:357-372.

58. Kashyap V, Morales A, Hongsermeier T: On implementing clinical decision support: achieving scalability and maintainability by combining business rules and ontologies. AMIA Annu Symp Proc 2006, 414-418.

59. Musen MA: Scalable software architectures for decision support. Methods Inf Med 1999, 38:229-238.

60. Clancey W: The Epistemology of a Rule Based Expert System: A Framework for Explanation. Artificial Intelligence 1983, 20:215-251.

61. Pearl J: Probabilistic Reasoning in Intelligent Systems: Networks of Plausible Inference San Francisco: Morgan Kaufmann Publishers, Inc 1988.

62. de Dombal FT, Leaper DJ, Staniland JR, McCann AP, Horrocks JC: Computer-aided diagnosis of acute abdominal pain. Br Med J 1972, 2:9-13.

63. Altschul SF, Madden TL, Schaffer AA, Zhang J, Zhang Z, Miller W, Lipman DJ: Gapped BLAST and PSI-BLAST: a new generation of protein database search programs. Nucleic Acids Res 1997, 25:3389-3402.

64. Allen JE, Majoros WH, Pertea M, Salzberg SL: JIGSAW, GeneZilla, and GlimmerHMM: puzzling out the features of human genes in the ENCODE regions. Genome Biol 2006, 7(Suppl 1:S9):1-13.

65. Kundaje A, Middendorf M, Shah M, Wiggins CH, Freund Y, Leslie C: A classification-based framework for predicting and analyzing gene regulatory response. BMC Bioinformatics 2006, 7(Suppl 1):S5.

66. Downing GJ, Boyle SN, Brinner KM, Osheroff JA: Information management to enable personalized medicine: stakeholder roles in building clinical decision support. BMC Med Inform Decis Mak 2009, 9:44.

67. Kawamoto K, Lobach DF, Willard HF, Ginsburg GS: A national clinical decision support infrastructure to enable the widespread and consistent practice of genomic and personalized medicine. BMC Med Inform Decis Mak 2009, 9:17.

68. Lee HJ, Hwang SI, Han SM, Park SH, Kim SH, Cho JY, Seong CG, Choe G: Image-based clinical decision support for transrectal ultrasound in the diagnosis of prostate cancer: comparison of multiple logistic regression, artificial neural network, and support vector machine. Eur Radiol 2009

69. Khorasani R: Clinical decision support in radiology: what is it, why do we need it, and what key features make it effective?. J Am Coll Radiol 2006, 3:142-143

70. De Dombal FT: Computer-aided decision support-glittering prospects, practical problems, and Pandora's box. Baillieres Clin Obstet Gynaecol 1990, 4:841-849.

71. Garg AX, Adhikari NK, McDonald H, Rosas-Arellano MP, Devereaux PJ, Beyene J, Sam J, Haynes RB: Effects of computerized clinical decision support systems on practitioner performance and patient outcomes: a systematic review. JAMA 2005, 293:1223-1238. 
72. Berlin A, Sorani M, Sim I: A taxonomic description of computerbased clinical decision support systems. J Biomed Inform 2006, 39:656-667.

73. Hunt DL, Haynes RB, Hanna SE, Smith K: Effects of computer-based clinical decision support systems on physician performance and patient outcomes: a systematic review. JAMA 1998, 280:1339-1346.

74. Sittig DF, Wright A, Osheroff JA, Middleton B, Teich JM, Ash JS, Campbell E, Bates DW: Grand challenges in clinical decision support. J Biomed Inform 2008, 41:387-392.

75. Short $D$, Frischer M, Bashford J: Barriers to the adoption of computerised decision support systems in general practice consultations: a qualitative study of GPs' perspectives. Int J Med Inform 2004, 73:357-362.

76. Kaplan B: Evaluating informatics applications-clinical decision support systems literature review. Int J Med Inform 2001, 64:15-37.

77. Fieschi M, Dufour JC, Staccini P, Gouvernet J, Bouhaddou O: Medical decision support systems: old dilemmas and new paradigms?. Methods Inf Med 2003, 42:190-198.

78. Payne TH: Computer decision support systems. Chest 2000, 118:47S-52S.

79. Manley DK, Bravata DM: A decision framework for coordinating bioterrorism planning: lessons from the BioNet program. Am J Disaster Med 2009, 4:49-57.

80. Buckeridge DL: Outbreak detection through automated surveillance: a review of the determinants of detection. J Biomed Inform 2007, 40:370-379.

81. Gesteland PH, Gardner RM, Tsui FC, Espino JU, Rolfs RT, James BC, Chapman WW, Moore AW, Wagner MM: Automated syndromic surveillance for the 2002 Winter Olympics. J Am Med Inform Assoc 2003, 10:547-554.

82. Wright A, Bates DW, Middleton B, Hongsermeier T, Kashyap V, Thomas SM, Sittig DF: Creating and sharing clinical decision support content with Web 2.0: Issues and examples. J Biomed Inform 2009, 42:334-346.

83. Watson MS, Epstein C, Howell RR, Jones MC, Korf BR, McCabe ER, Simpson JL: Developing a national collaborative study system for rare genetic diseases. Genet Med 2008, 10:325-329.

84. Allen J: Natural language understanding Redwood City, Calif:: Benjamin/ Cummings Pub. Co, 21995

85. Feldman R, Sanger J: The text mining handbook: advanced approaches in analyzing unstructured data Cambridge; New York: Cambridge University Press 2007.

86. Reiter E, Dale R: Building natural language generation systems Casmbridge, U.K New York: Cambridge University Press 2000.

87. Jurafsky $\mathrm{D}, \mathrm{Martin} \mathrm{JH}$ : Speech and language processing: an introduction to natural language processing, computational linguistics, and speech recognition Upper Saddle River, N.J.: Prentice Hall 2000.

88. Cohen KB, Hunter L: Getting started in text mining. PLoS Comput Biol 2008, 4:e20.

89. Scherf M, Epple A, Werner $\mathrm{T}$ : The next generation of literature analysis: integration of genomic analysis into text mining. Brief Bioinform 2005, 6:287-297.

90. Rzhetsky A, lossifov I, Koike T, Krauthammer M, Kra P, Morris M, Yu H, Duboue PA, Weng W, Wilbur WJ, Hatzivassiloglou V, Friedman C: GeneWays: a system for extracting, analyzing, visualizing, and integrating molecular pathway data. J Biomed Inform 2004, 37:43-53.

91. Dang PA, Kalra MK, Blake MA, Schultz TJ, Stout M, Lemay PR, Freshman DJ, Halpern EF, Dreyer KJ: Natural language processing using online analytic processing for assessing recommendations in radiology reports. J Am Coll Radiol 2008, 5:197-204.

92. Kahn CE Jr: Artificial intelligence in radiology: decision support systems. Radiographics 1994, 14:849-861.

93. Xu S, McCusker J, Krauthammer M: Yale Image Finder (YIF): a new search engine for retrieving biomedical images. Bioinformatics 2008, 24:1968-1970.

94. Dang PA, Kalra MK, Blake MA, Schultz TJ, Halpern EF, Dreyer KJ: Extraction of recommendation features in radiology with natural language processing: exploratory study. AJR Am J Roentgenol 2008, 191:313-320

95. Meystre SM, Savova GK, Kipper-Schuler KC, Hurdle JF: Extracting information from textual documents in the electronic health record: a review of recent research. Yearb Med Inform 2008, 128-144.

96. Cawsey AJ, Webber BL, Jones RB: Natural language generation in health care. J Am Med Inform Assoc 1997, 4:473-482.
97. Dalal M, Feiner S, McKeown K, Jordan D, Allen B, alSafadi Y: MAGIC: an experimental system for generating multimedia briefings about postbypass patient status. Proc AMIA Annu Fall Symp 1996, 684-688.

98. Jordan DA, McKeown KR, Concepcion K, Feiner SK, Hatzivassiloglou V: Generation and evaluation of intraoperative inferences for automated health care briefings on patient status after bypass surgery. J Am Med Inform Assoc 2001, 8:267-280.

99. Kukafka R, Bales ME, Burkhardt A, Friedman C: Human and automated coding of rehabilitation discharge summaries according to the International Classification of Functioning, Disability, and Health. J Am Med Inform Assoc 2006, 13:508-515.

100. Chapman WW, Dowling JN, Wagner MM: Generating a reliable reference standard set for syndromic case classification. J Am Med Inform Assoc 2005, 12:618-629.

101. Weeber M, Kors JA, Mons B: Online tools to support literature-based discovery in the life sciences. Brief Bioinform 2005, 6:277-286.

102. Swanson DR: Medical literature as a potential source of new knowledge. Bull Med Libr Assoc 1990, 78:29-37.

103. Rebholz-Schuhman D, Cameron G, Clark D, van Mulligen E, Coatrieux JL, Del Hoyo Barbolla E, Martin-Sanchez F, Milanesi L, Porro I, Beltrame F, Tollis I, Lei Van der J: SYMBIOmatics: synergies in Medical Informatics and Bioinformatics-exploring current scientific literature for emerging topics. BMC Bioinformatics 2007, 8(Suppl 1):S18.

104. MEDLINE/PubMed Baseline Repository. http://mbr.nlm.nih.gov/.

105. Lehmann HP: Aspects of electronic health record systems New York: Springer, 22006.

106. Hersh W: Evaluation of biomedical text-mining systems: lessons learned from information retrieval. Brief Bioinform 2005, 6:344-356.

107. Brennan PF, Aronson AR: Towards linking patients and clinical information: detecting UMLS concepts in e-mail. J Biomed Inform 2003, 36:334-341.

108. Huff SM: Clinical data exchange standards and vocabularies for messages. Proc AMIA Symp 1998, 62-67.

109. Cimino JJ, Zhu X: The practical impact of ontologies on biomedical informatics. Yearb Med Inform 2006, 124-135.

110. Klein GO: Standardization of health informatics-results and challenges. Methods Inf Med 2002, 41:261-270.

111. Mattheus R: European standardization efforts: an important framework for medical imaging. Eur J Radiol 1993, 17:28-37.

112. Hammond WE, Jaffe C, Kush RD: Healthcare standards development. The value of nurturing collaboration. J AHIMA 2009, 80:44-50, quiz 51-42.

113. Quackenbush J: Data reporting standards: making the things we use better. Genome Med 2009, 1:111.

114. Bodenreider O: Biomedical ontologies in action: role in knowledge management, data integration and decision support. Yearb Med Inform 2008, 67-79.

115. Rubin DL, Shah NH, Noy NF: Biomedical ontologies: a functional perspective. Brief Bioinform 2008, 9:75-90.

116. Blake J: Bio-ontologies-fast and furious. Nat Biotechnol 2004, 22:773-774.

117. Cimino JJ: Review paper: coding systems in health care. Methods Inf Med 1996, 35:273-284.

118. Peden AH: An overview of coding and its relationship to standardized clinical terminology. Top Health Inf Manage 2000, 21:1-9.

119. Eriksson H, Morin M, Jenvald J, Gursky E, Holm E, Timpka T: Ontology based modeling of pandemic simulation scenarios. Stud Health Technol Inform 2007, 129:755-759.

120. Brazma A, Hingamp P, Quackenbush J, Sherlock G, Spellman P, Stoeckert C, Aach J, Ansorge W, Ball CA, Causton HC, Gaasterland T, Glenisson P, Holstege FC, Kim IF, Markowitz V, Matese JC, Parkinson H, Robinson A Sarkans U, Schulze-Kremer S, Stewart J, Taylor R, Vilo J, Vingron M: Minimum information about a microarray experiment (MIAME)-toward standards for microarray data. Nat Genet 2001, 29:365-371.

121. Bidgood WD Jr, Horii SC, Prior FW, Van Syckle DE: Understanding and using DICOM, the data interchange standard for biomedical imaging. J Am Med Inform Assoc 1997, 4:199-212.

122. Blobel BG, Engel K, Pharow P: Semantic interoperability-HL7 Version 3 compared to advanced architecture standards. Methods Inf Med 2006, 45:343-353.

123. Hammond WE: Health Level 7: an application standard for electronic medical data exchange. Top Health Rec Manage 1991, 11:59-66. 
124. Rosenbloom ST, Miller RA, Johnson KB, Elkin PL, Brown SH: A model for evaluating interface terminologies. J Am Med Inform Assoc 2008, 15:65-76.

125. Wade G, Rosenbloom ST: The impact of SNOMED CT revisions on a mapped interface terminology: terminology development and implementation issues. J Biomed Inform 2009, 42:490-493.

126. Richesson RL, Krischer J: Data standards in clinical research: gaps, overlaps, challenges and future directions. J Am Med Inform Assoc 2007, 14:687-696.

127. WHO International Classification of Diseases. http://www.who.int/ classifications/icd/en/.

128. Lahteenmaki J, Leppanen J, Kaijanranta H: Interoperability of personal health records. Conf Proc IEEE Eng Med Biol Soc 2009, 1:1726-1729.

129. Mykkanen J, Korpela M, Ripatti S, Rannanheimo J, Sorri J: Local, regional and national interoperability in hospital-level systems architecture. Methods Inf Med 2007, 46:470-475.

130. Klein GO, Sottile PA, Endsleff F: Another HISA-the new standard: health informatics-service architecture. Stud Health Technol Inform 2007, 129:478-482.

131. Marchibroda JM: Health information exchange policy and evaluation. J Biomed Inform 2007, 40:511-16.

132. Ohmann C, Kuchinke W: Future developments of medical informatics from the viewpoint of networked clinical research. Interoperability and integration. Methods Inf Med 2009, 48:45-54.

133. Lorence D, Sivaramakrishnan A: Technology assessment of resources for the emerging US e-health infrastructure: a proposed interoperability model. Int J Electron Healthc 2006, 2:291-303.

134. ISO TC215 Health Informatics. http://www.iso.org/iso/ iso_technical_committee?commid=54960.

135. Prokosch HU, Ganslandt T: Perspectives for medical informatics. Reusing the electronic medical record for clinical research. Methods Inf Med 2009, 48:38-44.

136. Burgun A, Bodenreider O: Accessing and integrating data and knowledge for biomedical research. Yearb Med Inform 2008, 91-101.

137. Harris MA: Developing an ontology. Methods Mol Biol 2008, 452:111-124.

138. Lindberg DA, Humphreys BL, McCray AT: The Unified Medical Language System. Methods Inf Med 1993, 32:281-291.

139. Humphreys BL, Lindberg DA: The UMLS project: making the conceptual connection between users and the information they need. Bull Med Libr Assoc 1993, 81:170-177.

140. Rubin DL, Lewis SE, Mungall CJ, Misra S, Westerfield M, Ashburner M, Sim I, Chute CG, Solbrig H, Storey MA, Smith B, Day-Richter J, Noy NF, Musen MA: National Center for Biomedical Ontology: advancing biomedicine through structured organization of scientific knowledge. OMICS 2006, 10:185-198.

141. Musen M, Shah N, Noy N, Dai B, Dorf M, Griffith N, Buntrock JD, Jonquet C, Montegut MJ, Rubin DL: BioPortal: Ontologies and Data Resources with the Click of a Mouse. AMIA Annu Symp Proc 2008, 1223-1224.

142. Pathak J, Solbrig HR, Buntrock JD, Johnson TM, Chute CG: LexGrid: A Framework for Representing, Storing, and Querying Biomedical Terminologies from Simple to Sublime. J Am Med Inform Assoc 2009, 16:305-315.

143. Bug WJ, Ascoli GA, Grethe JS, Gupta A, Fennema-Notestine C, Laird AR, Larson SD, Rubin D, Shepherd GM, Turner JA, Martone ME: The NIFSTD and BIRNLex vocabularies: building comprehensive ontologies for neuroscience. Neuroinformatics 2008, 6:175-194.

144. Manning CD, Raghavan $\mathrm{P}$, Schütze $\mathrm{H}$ : Introduction to information retrieval New York: Cambridge University Press 2008

145. Siadaty MS, Harrison JH Jr: Multi-database mining. Clin Lab Med 2008, 28:73-82, vi.

146. Louie B, Mork P, Martin-Sanchez F, Halevy A, Tarczy-Hornoch P: Data integration and genomic medicine. J Biomed Inform 2007, 40:5-16.

147. PubMed. http://www.pubmed.gov.

148. Galperin MY, Cochrane GR: Nucleic Acids Research annual Database Issue and the NAR online Molecular Biology Database Collection in 2009. Nucleic Acids Res 2009, 37:D1-4.

149. Cadag E, Louie B, Myler PJ, Tarczy-Hornoch P: Biomediator data integration and inference for functional annotation of anonymous sequences. Pac Symp Biocomput 2007, 343-354.

150. Muller H, Michoux N, Bandon D, Geissbuhler A: A review of content-based image retrieval systems in medical applications-clinical benefits and future directions. Int J Med Inform 2004, 73:1-23.
151. Hsu W, Antani S, Long LR, Neve L, Thoma GR: SPIRS: a Web-based image retrieval system for large biomedical databases. Int J Med Inform 2009, 78(Suppl 1):S13-24.

152. Maviglia SM, Yoon CS, Bates DW, Kuperman G: KnowledgeLink: impact of context-sensitive information retrieval on clinicians' information needs. $J$ Am Med Inform Assoc 2006, 13:67-73.

153. Cimino J: Infobuttons: anticipatory passive decision support. AMIA Annu Symp Proc 2008, 1203-1204

154. O'Carroll PW: Public health informatics and information systems New York: Springer 2003

155. Zeng QT, Crowell J, Plovnick RM, Kim E, Ngo L, Dibble E: Assisting consumer health information retrieval with query recommendations. $J$ Am Med Inform Assoc 2006, 13:80-90.

156. Jacquemart $P$, Zweigenbaum $P$ : Towards a medical question-answering system: a feasibility study. Stud Health Technol Inform 2003, 95:463-468.

157. Ruttenberg A, Clark T, Bug W, Samwald M, Bodenreider O, Chen H, Doherty D, Forsberg K, Gao Y, Kashyap V, Kinoshita J, Luciano J, Marshall MS, Ogbuji C, Rees J, Stephens S, Wong GT, Wu E, Zaccagnini D, Hongsermeier T, Neumann E, Herman I, Cheung KH: Advancing translational research with the Semantic Web. BMC Bioinformatics 2007, 8(Suppl 3):S2.

158. Smith AK, Cheung KH, Yip KY, Schultz M, Gerstein MK: LinkHub: a Semantic Web system that facilitates cross-database queries and information retrieval in proteomics. BMC Bioinformatics 2007, 8(Suppl 3): S5.

159. Mirhaji P, Zhu M, Vagnoni M, Bernstam EV, Zhang J, Smith JW: Ontology driven integration platform for clinical and translational research. $B M C$ Bioinformatics 2009, 10(Suppl 2):S2.

160. Honigman B, Lee J, Rothschild J, Light P, Pulling RM, Yu T, Bates DW: Using computerized data to identify adverse drug events in outpatients. J Am Med Inform Assoc 2001, 8:254-266.

161. Mangalampalli A, Rama C, Muthiyalian R, Jain AK: High-end clinical domain information systems for effective healthcare delivery. Int J Electron Healthc 2007, 3:208-219.

162. Ebidia A, Mulder C, Tripp B, Morgan MW: Getting data out of the electronic patient record: critical steps in building a data warehouse for decision support. Proc AMIA Symp 1999, 745-749.

163. Ledbetter CS, Morgan MW: Toward best practice: leveraging the electronic patient record as a clinical data warehouse. J Healthc Inf Manag 2001, 15:119-131.

164. Greenes RA, Pappalardo AN, Marble CW, Barnett GO: Design and implementation of a clinical data management system. Comput Biomed Res 1969, 2:469-485.

165. Barnett GO: The application of computer-based medical-record systems in ambulatory practice. N Engl J Med 1984, 310:1643-1650.

166. Institute of Medicine (U.S.). Committee on Improving the Patient Record, Dick RS, Steen EB, Detmer DE: The computer-based patient record: an essential technology for health care Washington, D.C.: National Academy Press 1997.

167. Sax U, Schmidt S: Integration of genomic data in Electronic Health Records-opportunities and dilemmas. Methods Inf Med 2005, 44:546-550

168. Thorisson GA, Muilu J, Brookes AJ: Genotype-phenotype databases: challenges and solutions for the post-genomic era. Nat Rev Genet 2009, 10:9-18.

169. Hoffman MA: The genome-enabled electronic medical record. J Biomed Inform 2007, 40:44-46.

170. Law MY, Liu B, Chan LW: Informatics in radiology: DICOM-RT-based electronic patient record information system for radiation therapy. Radiographics 2009, 29:961-972

171. Liu BJ: A knowledge-based imaging informatics approach for managing proton beam therapy of cancer patients. Technol Cancer Res Treat 2007, 6:77-84.

172. Liu BJ, Law MY, Documet J, Gertych A: Image-assisted knowledge discovery and decision support in radiation therapy planning. Comput Med Imaging Graph 2007, 31:311-321.

173. Prevedello LM, Andriole KP, Khorasani RR: Informatics in radiology: integration of the medical imaging resource center into a teaching hospital network to allow single sign-on access. Radiographics 2009, 29:973-979.

174. Furuie SS, Rebelo MS, Moreno RA, Santos M, Bertozzo N, Motta GH, Pires FA, Gutierrez MA: Managing medical images and clinical 
information: InCor's experience. IEEE Trans Inf Technol Biomed 2007, 11:17-24.

175. Iglehart JK: Budgeting for change-Obama's down payment on health care reform. N Engl J Med 2009, 360:1381-1383.

176. Shekelle PG, Morton SC, Keeler EB: Costs and benefits of health information technology. Evid Rep Technol Assess (Full Rep) 2006, 1-71.

177. Chaudhry B, Wang J, Wu S, Maglione M, Mojica W, Roth E, Morton SC, Shekelle PG: Systematic review: impact of health information technology on quality, efficiency, and costs of medical care. Ann Intern Med 2006, 144:742-752

178. Balfour DC, Evans S, Januska J, Lee HY, Lewis SJ, Nolan SR, Noga M, Stemple C, Thapar K: Health information technology-results from a roundtable discussion. J Manag Care Pharm 2009, 15:10-17.

179. Poon EG, Jha AK, Christino M, Honour MM, Fernandopulle R, Middleton B, Newhouse J, Leape L, Bates DW, Blumenthal D, Kaushal R: Assessing the level of healthcare information technology adoption in the United States: a snapshot. BMC Med Inform Decis Mak 2006, 6:1.

180. Lombardo J, Burkom H, Elbert E, Magruder S, Lewis SH, Loschen W, Sari J, Sniegoski C, Wojcik R, Pavlin J: A systems overview of the Electronic Surveillance System for the Early Notification of Community-Based Epidemics (ESSENCE II). J Urban Health 2003, 80:i32-42.

181. Bravata DM, McDonald KM, Smith WM, Rydzak C, Szeto H, Buckeridge DL, Haberland C, Owens DK: Systematic review: surveillance systems for early detection of bioterrorism-related diseases. Ann Intern Med 2004, 140:910-922.

182. Poissant L, Pereira J, Tamblyn R, Kawasumi Y: The impact of electronic health records on time efficiency of physicians and nurses: a systematic review. J Am Med Inform Assoc 2005, 12:505-516.

183. Hayrinen K, Saranto K, Nykanen P: Definition, structure, content, use and impacts of electronic health records: a review of the research literature. Int J Med Inform 2008, 77:291-304.

184. Persell DJ, Robinson $\mathrm{CH}$ : Detection and early identification in bioterrorism events. Fam Community Health 2008, 31:4-16.

185. Tang PC, Ash JS, Bates DW, Overhage JM, Sands DZ: Personal health records: definitions, benefits, and strategies for overcoming barriers to adoption. J Am Med Inform Assoc 2006, 13:121-126.

186. Ball MJ, Gold J: Banking on health: Personal records and information exchange. J Healthc Inf Manag 2006, 20:71-83.

187. Eysenbach G: Medicine 2.0: social networking, collaboration, participation, apomediation, and openness. J Med Internet Res 2008, 10: e22.

188. Detmer D, Bloomrosen M, Raymond B, Tang P: Integrated personal health records: transformative tools for consumer-centric care. BMC Med Inform Decis Mak 2008, 8:45.

189. Johnston D, Kaelber D, Pan EC, Bu D, Shah S, Hook JM, Middleton B: A framework and approach for assessing the value of personal health records (PHRs). AMIA Annu Symp Proc 2007, 374-378.

190. Wasson K, Cook ED, Helzlsouer K: Direct-to-consumer online genetic testing and the four principles: an analysis of the ethical issues. Ethics Med 2006, 22:83-91.

191. Williams-Jones B: Where there's a web, there's a way: commercial genetic testing and the Internet. Community Genet 2003, 6:46-57.

192. Weitzman ER, Kaci L, Mandl KD: Acceptability of a personally controlled health record in a community-based setting: implications for policy and design. J Med Internet Res 2009, 11:e14.

193. Halamka JD, Mandl KD, Tang PC: Early experiences with personal health records. J Am Med Inform Assoc 2008, 15:1-7.

194. Zerhouni EA: Clinical research at a crossroads: the NIH roadmap. $J$ Investig Med 2006, 54:171-173.

195. Zerhouni EA: US biomedical research: basic, translational, and clinical sciences. JAMA 2005, 294:1352-1358.

196. Choi BC, Pak AW: Multidisciplinarity, interdisciplinarity and transdisciplinarity in health research, services, education and policy: 1 . Definitions, objectives, and evidence of effectiveness. Clin Invest Med 2006, 29:351-364.

197. Choi BC, Pak AW: Multidisciplinarity, interdisciplinarity, and transdisciplinarity in health research, services, education and policy: 2 . Promotors, barriers, and strategies of enhancement. Clin Invest Med 2007, 30:E224-232

198. Choi BC, Pak AW: Multidisciplinarity, interdisciplinarity, and transdisciplinarity in health research, services, education and policy: 3 .
Discipline, inter-discipline distance, and selection of discipline. Clin Invest Med 2008, 31:E41-48.

199. van Bemmel JH: The young person's guide to biomedical informatics. Methods Inf Med 2006, 45:671-680.

200. Friedman CP, Altman RB, Kohane IS, McCormick KA, Miller PL, Ozbolt JG, Shortliffe EH, Stormo GD, Szczepaniak MC, Tuck D, Williamson J: Training the next generation of informaticians: the impact of "BISTI" and bioinformatics-a report from the American College of Medical Informatics. J Am Med Inform Assoc 2004, 11:167-172.

201. Johnson SB, Friedman RA: Bridging the gap between biological and clinical informatics in a graduate training program. J Biomed Inform 2007, 40:59-66.

202. Hovenga EJ: Global health informatics education. Stud Health Technol Inform 2000, 57:3-14

203. Reichertz PL: Preparing for change: concepts and education in medical informatics. Comput Methods Programs Biomed 1987, 25:89-101.

204. Altman RB: The interactions between clinical informatics and bioinformatics: a case study. J Am Med Inform Assoc 2000, 7:439-443.

205. Maojo V, Martin-Sanchez F: Bioinformatics: towards new directions for public health. Methods Inf Med 2004, 43:208-214.

206. Lyon J, Giuse NB, Williams A, Koonce T, Walden R: A model for training the new bioinformationist. J Med Libr Assoc 2004, 92:188-195.

207. Masys DR: Effects of current and future information technologies on the health care workforce. Health Aff (Millwood) 2002, 21:33-41.

208. Ball MJ, Douglas JV: Informatics programs in the United States and abroad. MD Comput 1990, 7:172-175.

209. Severtson DJ, Pape L, Page CD Jr, Shavlik JW, Phillips GN Jr, Flatley Brennan P: Biomedical informatics training at the University of Wisconsin-Madison. Yearb Med Inform 2007, 149-156.

210. Greenes RA, Panchanathan S, Patel V, Silverman H, Shortliffe EH: Biomedical informatics in the desert-a new and unique program at Arizona State University. Yearb Med Inform 2008, 150-156.

211. Hersh WR: The full spectrum of biomedical informatics education at Oregon Health \& Science University. Methods Inf Med 2007, 46:80-83.

212. Kane MD, Brewer JL: An information technology emphasis in biomedical informatics education. J Biomed Inform 2007, 40:67-72.

213. Gerstein M, Greenbaum D, Cheung K, Miller PL: An interdepartmental Ph. D. program in computational biology and bioinformatics: the Yale perspective. J Biomed Inform 2007, 40:73-79.

214. Mantas J, Ammenwerth E, Demiris G, Hasman A, Haux R, Hersh W, Hovenga E, Lun KC, Marin H, Martin-Sanchez F, Wright G: Recommendations of the International Medical Informatics Association (IMIA) on Education in Biomedical and Health Informatics. Methods Inf Med 2010, 49

215. King SB, MacDonald K: Metropolis redux: the unique importance of library skills in informatics. J Med Libr Assoc 2004, 92:209-217.

216. Stein L: Creating a bioinformatics nation. Nature 2002, 417:119-120.

217. Contemporary issues in medicine-medical informatics and population health: report II of the Medical School Objectives Project. Acad Med 1999, 74:130-141.

218. Yasnoff WA, O'Carroll PW, Koo D, Linkins RW, Kilbourne EM: Public health informatics: improving and transforming public health in the information age. J Public Health Manag Pract 2000, 6:67-75.

219. Patel VL, Branch T, Cimino A, Norton C, Cimino JJ: Participant perceptions of the influences of the NLM-sponsored Woods Hole medical informatics course. J Am Med Inform Assoc 2005, 12:256-262.

220. Hersh W, Williamson J: Educating 10,000 informaticians by 2010: the AMIA $10 \times 10$ program. Int J Med Inform 2007, 76:377-382.

doi:10.1186/1479-5876-8-22

Cite this article as: Sarkar: Biomedical informatics and translational medicine. Journal of Translational Medicine 2010 8:22. 